\title{
Structural Consolidation of Aghios Konstantinos Church, Athens
}

\author{
By Danae Phaedra Pocobelli* \\ Maria Grazia Turco ${ }^{\dagger}$
}

\begin{abstract}
This paper is based on the Master's thesis work conducted by D.Ph. Pocobelli in Sapienza University of Rome in 2014. Although the Aghios Konstantinos Church is currently under restoration processes, this research took place before the restoration of the dome, now finalised. Aghios Konstantinos Church was designed by architect Lysandros Kaftantzoglou at the end of the 19th century. It was being built for more than 20 years, and it was completed after its author's death. The main façade is characterised by three different levels: the ground floor, the mezzanine or gynaeceum, and the dome. The inner space is organised into three naves and a transept; the intersection between the central nave and the transept is covered by the dome. The church has suffered several damages caused mainly by two strong earthquakes that took place in the surroundings of Athens. The first earthquake occurred in 1981 in Alkyonides Islands, with a magnitude of 6.6 Richter. The second one happened in 1999 in Ano Liosia, with a magnitude of 5.5 Richter. These events caused major structural damages, concentrated on the dome, the main piles and the arches supporting the vault. On top of that, major fractures were also produced by the weight of the dome itself, which has been built with greater dimensions and heavier materials than the ones originally calculated by Kaftantzoglou. The piles have deep horizontal fractures on their bases, and superficial diagonal fractures under the cornice. The arches supporting the vault have transversal fractures that become deeper in correspondence of the keystone. Finally, the dome reveals a continuous horizontal fracture on the tambour, and vertical cracks that run from the architraves upwards. The interventions proposed in this paper are a Fibre Reinforced Polymer (FRP) hooping for the dome and stainless steel chaining bars for the arches.
\end{abstract}

\section{Introduction}

For a Methodological Preface

The restoration project of the Aghios Konstantinos church in Athens (1871-1893, Lysander Kaftantzoglou) is based on a preliminary - and crucial - phase of close examination and collection of "objective" data. This phase takes place through a building survey and its graphical elaboration. This is a fundamental point to enable dimensional, symbolic and functional elements understanding. Moreover, it supports construction techniques, materials, and historical layers knowledge.

\footnotetext{
* PhD Candidate, UCL/Sapienza University of Rome, UK/Italy.

${ }^{\dagger}$ Associate Professor, Sapienza University of Rome, Italy.
} 
The above-mentioned phase is a preparatory operation that is essential to reach the "critical" awareness needed to clarify, determine and carry out any restoration operations. These interventions are usually characterised by specific conservation issues, and their solutions can be diverse and several.

In the work illustrated in this paper, we show all the aspects that concur to shape heritage building understanding. These aspects include historical, cultural and architectural features. Moreover, more specialistic elements are considered, such as construction techniques, static issues, structural peculiarities and past consolidation interventions close examinations.

Aghios Konstantinos church's knowledge process started with a general study of the building and of the elements that affect its structural behaviour. The research was carried out through direct surveys, which enabled diagnosis, calculus and simulation model elaborations. This is the starting point to create the architectural project, which takes shape from design, abstraction and formalisation of structural and architectural elements. Specifically, crack survey and historical layers identification were the basic elements that allowed mechanical model choice and its reliability assessment.

This deep analysis focused on the structural instability causes and their related structural behaviour. This is an essential prerequisite for delivering an appropriate and compatible intervention proposal. The intervention proposal should be as less "invasive" as possible and, in the meantime, it should be respectful of traditional construction techniques.

These criteria are common in restoration practice. Indeed, there is no need to have to recourse to conceptual or methodologic paths that are different from the ones characterising traditional restoration and conservation operations. As a matter of fact, structural elements are part and parcel of buildings - and their history. Static mechanisms and structural history understanding is a crucial element for the development of a historical-critical knowledge of the building.

Static issues require in-depth analysis as well. It is necessary to build a knowledge that is comprehensive of architectural elements, material characterisation and historical layers of consolidation interventions. This knowledge needs to be built according to restoration criteria and processes, i.e., through archival research, survey, and extensive analysis of more specialistic aspects (such as typological, constructive, material and structural elements, as they are pivotal parts of heritage buildings).

The "material conservation" of the structure has been a crucial moment during the project. This operation was carried out through alterations, pathologies and macro-degradations analyses. The above-mentioned analysis phase was complex, as weathering phenomena take place in different formats and in different areas of the building.

The project outline took shape through determination of principles and operational strategies consistent with - and respectful of - traditional construction techniques. Balance between structural consolidation and adjustment to technical guidelines and policies was crucial. 
Some practitioners, indeed, highlight very often the "presumed antinomy restoration/consolidation." "However, this contrast is only apparent if both the aspect and the structural issues are identified as "static concerns of the restoration practice" during conservation action. These concerns should, therefore, be resolved with a collaborative approach - which is complex, but not difficult , merging technical-scientific aspects with historical-critical argumentations.

Hence, we were aware that consolidation operation is not only a technic action. During structural intervention of Aghios Konstantinos church, we assessed:

- Building's historic significance, within the $18^{\text {th }}$-century culture;

- its typological characterisation in historic and technic context. Specifically, we researched punctual correspondence between each building element with the state of the art, the construction methodology, the material manufacturing techniques, the author's education, up to tasks and workers' roles definition. All these topics were compared within the range of buildings designed by Kaftantzoglou.

Additionally, we processed the needed structural calculations, and we examined structural elements, damage, degradation, focusing on element consistency analysis.

Through the specific case of Aghios Konstantinos church, we faced issues that are common in consolidation restoration practice - zooming in the building's identity knowledge and in its conservation.

Our consolidation proposal highlights the need for structural restoration practice to lean towards:

- reinforcement setups for critical elements, to improve the whole static behaviour;

- recognition - within the original structural strategy - of integration interventions that enable minimum and punctual static improvements. These should be structurally consistent with the original system and the following adjustments;

- identification of structural solutions that are diversified in relation to the heritage building's conservation condition.

Concerning the project, we tried to fulfil most peculiar criteria for restoration interventions, such as "non-invasiveness", compatibility, efficacy, reversibility and economic sustainability. We, therefore, propose solutions that are based on compatibility with qualities and characters of both the building and the place where it stands.

Via these synthetic reflections, it follows that the restoration discipline falls within the debate, the culture and the structural practice of conservation

1. S. D'Avino, "Patrimonio Edilizio: Quale Compromesso Tra Conservazione E Adeguamento Sismico?" Il Giornale dell'Architettura. Com, no. 13 (2016). 
- trying to interact with construction science and construction technique subjects, and trying to establish a balanced collaboration between those.

On top of that, the restoration discipline highlights how the project needs to be central, and how it is considered as a "critical operation".

The above-mentioned operations do not foreshadow any research on materials and technology renouncement. On the contrary, they experiment with new systems and new approaches - always considering those historic and artistic "values" previously detected in the building. Likewise, they respect the principle of transmission to future generations, conceived according to discretion and historic continuity.

Our project, therefore, has avoided complex and in full reconstructions. Nevertheless, it has addressed preventive and minimal interventions, which base their effectiveness on the building's specific knowledge.

A certain operative reference can be found in Antonino Giuffrè's words: "The path to be followed is clear: in the first place, we need to know what to conserve, and from this knowledge, we need to derive with certainty how to conserve." $" 2$

\section{Background}

The Architect

Lysander Kaftantzoglou was born in Thessaloniki in 1811 to a family of rich merchants. ${ }^{3}$ His father was Greek, while his mother had French origins. ${ }^{4}$ Since his childhood, he got used to European culture - sign that will become distinctive in its philosophy.

Between 1824 and 1836 he moved to Rome to attend the Architecture faculty in the Accademia di San Luca. ${ }^{5}$

In 1838 Kaftantzoglou moved to Athens, as he was hoping to be actively involved in the construction of the new city. ${ }^{6}$ However, his expectations were betrayed, since in that period Athens was full of Northern-European architects who were employed in the main architectural works ${ }^{7}$. Disappointed, he moved to Istanbul, where he managed to obtain many works, and he was finally able to put into practice his principles. ${ }^{8}$

2. A. Giuffrè, "Sicurezza E Conservazione Dei Centri Storici. Il Caso Di Ortigia," in Leggendo Il Libro Delle Antiche Architetture. Aspetti Statici Del Restauro. Saggi Di A. Giuffrè 1985-1997 (ed.) C. F. Carocci and C. Tocci. Rome: Laterza, 2010.

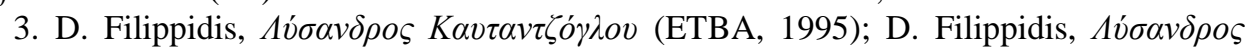

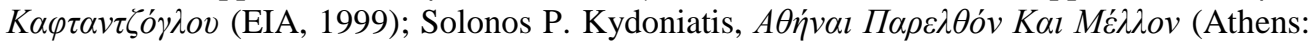



4. Filippidis, $\Lambda v ́ \sigma \alpha \nu \delta \rho o \varsigma K \alpha \varphi \tau \alpha v \tau \zeta o ́ \gamma \lambda o v, 1999$.

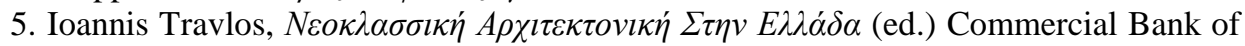

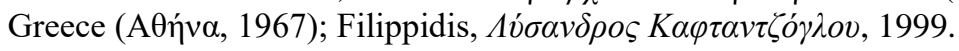





8. Ibid. 
In 1843 Kaftantzoglou moved back to Athens, where he became the Polytechnic Director - position kept until 1862. ${ }^{9}$ These were his more productive years: most of his works were conceived during this period, as he had become a élite personality. He died in Athens in $1885 .^{10}$

\section{Kaftantzoglou's Thought}

Kaftantzoglou actively participated in the cultural ferment that characterised Athens during the end of the $18^{\text {th }}$ century - since Greece had just come out the Ottoman rule after 400 years, there was an enthusiastic and philo-European mood all over the country. ${ }^{1}$

Kaftantzoglou himself, due to his studies in Rome, was keen on adapting Greek culture to European, ${ }^{12}$ always considering the willing of Ancient glory re-birth, similarly to what happened during the Italian Renaissance. Indeed, Ancient Greek art was considered as the perfection prototype, and it should be regarded as a model to emulate. ${ }^{13}$

Despite he was considerably famous while alive, once he died he got almost forgotten. This happened because Athens was attracting many NorthernEuropean architects, who left a valuable and original built heritage, ${ }^{14}$ compared to which Kaftantzoglou's work seems to be inveterate neoclassicism without any outstanding innovation. ${ }^{15}$ However, with a deeper analysis, it is possible to note that Kaftantzoglou's projects are characterised by the manifestation of the Byzantine tradition in a neoclassical variant, ${ }^{16}$ with "expressivity" and "lyricism."17

\section{Aghios Konstantinos Church (1871-1893)}

Different researchers (Filippidis, Turco and Pocobelli - just to cite few) have been studying Aghios Konstantinos church, and an extensive description - see below - can be provided, following their publications. ${ }^{18}$

Aghios Konstantinos is a Latin cross three-nave church. It measures $43.40 \mathrm{~m}$ in length, $32.10 \mathrm{~m}$ in width, and circa $35 \mathrm{~m}$ in height (up to the dome). The central nave terminates with an apse. There is a transect, which dimensions 1999.



10. Ibid.

11. Ibid.

12. Ibid.

13. Ibid.

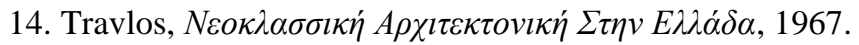

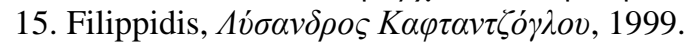

16. Filippidis, $\Lambda v ́ \sigma \alpha v \delta \rho o \varsigma K \alpha v \tau \alpha v \tau \zeta o ́ \gamma \lambda o v, 1995$.

17. Filippidis, $\Lambda v ́ \sigma \alpha v \delta \rho o \varsigma K \alpha \varphi \tau \alpha \nu \tau \zeta o ́ \gamma \lambda o v, 1999$.

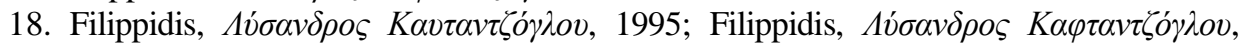


Pocobelli, "Aghios Konstantinos Church in Athens: Conservation Planning," in 3rd International Multidisciplinary Scientific Conference on Social Sciences and Arts SGEM2016, Www.sgem social.org, SGEM2016 Conference Proceedings. 43-50, 2016. 
are inferior to the nave ones, as it is a Latin cross structure (see Figure 1). The intersection between the transect and the central nave is covered by a dodecagonal dome. The dome is supported by a tambour, and immediately underneath it, there are four pillars connected to each other through round arches. The church is a two-storey building: the lateral naves are covered by a mezzanine, used as a gynaeceum in the past years. Moreover, there is a lowerground floor with a crypt, which is currently used as office lounges.



Figure 1. Ground Floor Plan

Source: SGEM 2016 Conference Proceedings. ${ }^{19}$

The main façade can be divided into three levels: the nave level, the mezzanine level, and the roof level (see Figure 2). The roof is a flat-type one, with a dome and two bell towers. The lower part of the façade is characterised by extensive use of marble. However, at some point, there might have been a fund cut, as the upper part was realised using stuccoes and plaster, trying to emulate marble texture and shape.

Through Aghios Konstantinos church Kaftantzoglou had the chance to design a church according to his principles and his aesthetics and in complete freedom. The result is an imposing and huge neoclassical church. ${ }^{20}$ External surfaces are characterised by the thorough use of marble, which gives the massive effect so much criticised. ${ }^{21}$ Nevertheless, Kaftantzoglou, through this project, tried to put into practice his idea of a new Greek style. Aghios

19. Turco and Pocobelli, "Aghios Konstantinos Church in Athens: Conservation Planning," 2016.

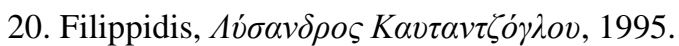

21. Ibid. 
Konstantinos church is a Byzantine church with a neoclassical rhythm, ${ }^{22}$ enhanced using Corinthian order. ${ }^{23}$

The church has suffered severe damages caused by the earthquakes that hit Athens in 1981 and in 1999.

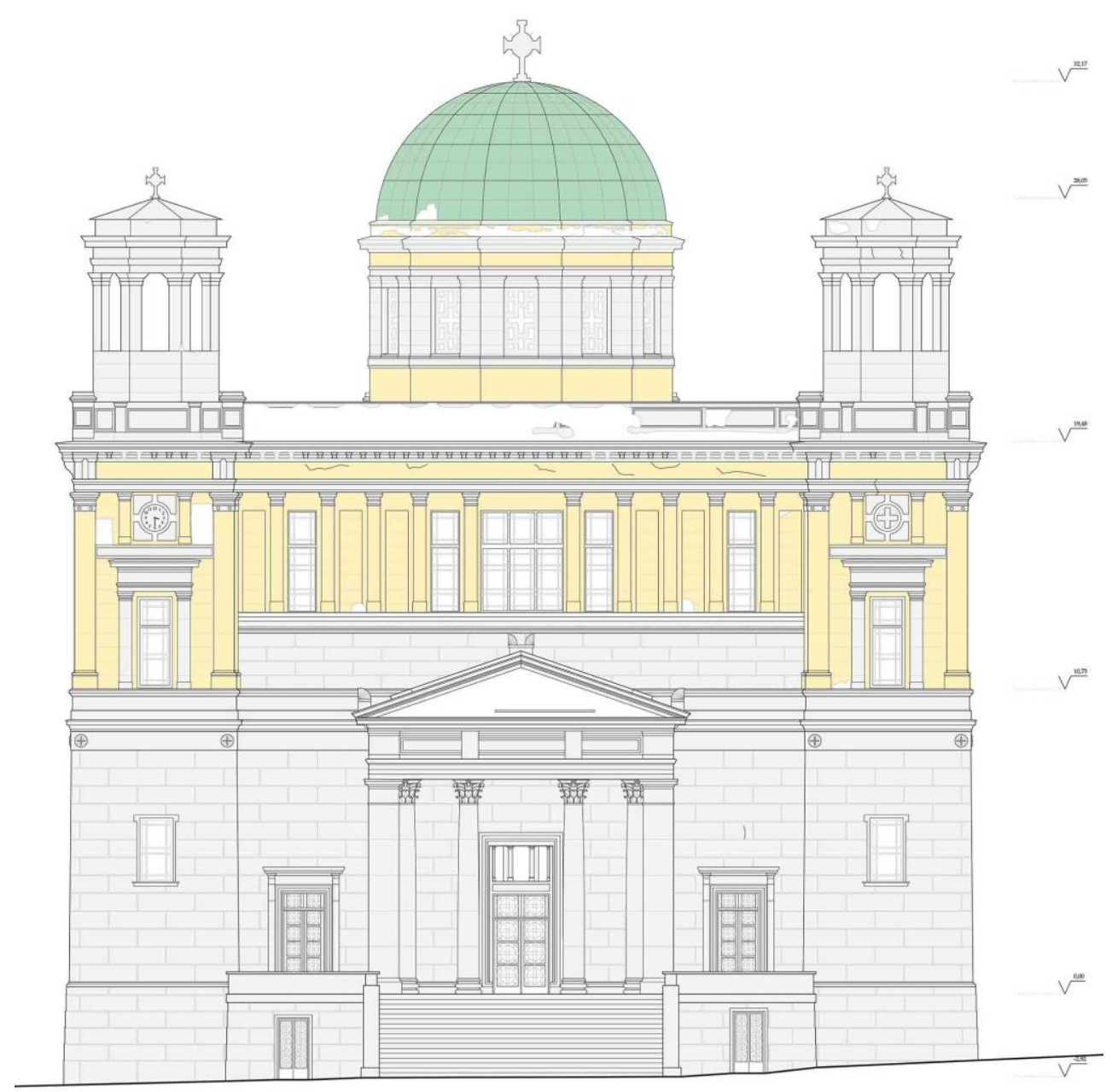

Figure 2. Main Façade Prospect (Colour Label for Materials: Grey = Marble, Yellow $=$ Stuccoes and Plaster, Green $=$ Copper $)$

Source: SGEM 2016 Conference Proceedings, ${ }^{24}$ colours modified by author.

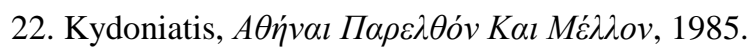

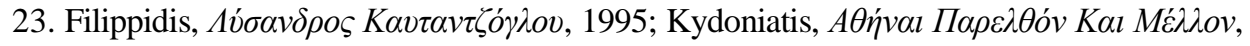
1985.

24. Turco and Pocobelli, "Aghios Konstantinos Church in Athens: Conservation Planning," 2016. 
The Earthquakes

Earthquake in Alkyonides Islands, $24^{\text {th }}$ of February 1981

At $22: 53$ UTC +2 of the $24^{\text {th }}$ of February of 1981 the first earth tremor happened. ${ }^{25}$ The earthquake measured 6.6 on the Richter scale. ${ }^{26}$ After few hours, at 4:35 UCT+2, a second tremor shook the Alkyonides Islands area, this time with a magnitude of 6.3 on the Richter scale. ${ }^{27}$

The Alkyonides Islands are pinpointed in the east side of the Corinth Gulf, and they are about $20 \mathrm{~km}$ north from Corinth, and $70 \mathrm{~km}$ west of Athens. ${ }^{28}$

The hypocenter was at a depth of $17.60 \mathrm{~km} .{ }^{29}$ There have been aftershocks until two weeks after the mainshock, ${ }^{30}$ and they had a magnitude of $5 / 6.2$ on the Richer scale. $^{31}$

This earthquake caused fractures in the Earth's crust for a length of over $30 \mathrm{~km}$ in the area close to Perachora and Loutraki, and in the north-east of the Alkyonides Islands. ${ }^{32}$

There have been surveyed damages in a radius of $100 \mathrm{~km}$ from the epicentre, especially in the Loutraki area: circa 8,500 buildings have suffered severe damages, while light damages have been detected in over 10,000 buildings. ${ }^{33}$ It is believed that big cities did not have any severe damages specifically, in Athens damages were apparently limited to few edifices and to non-structural components. ${ }^{34}$ In Corinth, damages were considered negligible, chiefly because of the adjustments that took place because of a severe antiseismic policy developed after the 1928 earthquake. ${ }^{35}$

As mentioned above, most damages took place in Loutraki, which is a well-known touristic destination. It is believed that the cause of extensive collapses in Loutraki's buildings is due to the lack of structural hardenings on ground floors. ${ }^{36}$ Surveys carried out in collapsed buildings revealed lack of

25. G. Berz and E. Hettler, Earthquakes in Greece, February/March 1981 (Munich, 1981); Umesh Chandra, Conrith, Greece Earthquake of February 24, 1981, 1981.

26. Berz and Hettler, Earthquakes in Greece, February/March 1981, 1981; James O. Jirsa and Gregg E. Brandow, The Greeke Earthquakes of February 24 and 25, 1981. A Brief Reconnaissance Report, 1981.

27. Ibid.

28. Berz and Hettler, Earthquakes in Greece, February/March 1981, 1981.

29. Ibid.

30. Norman Tifrod, Earthquakes and Ground Rupture, Eastern Gulf of Corinth Region, Greece, 1981; Berz and Hettler, Earthquakes in Greece, February/March 1981, 1981.

31. Jirsa and Brandow, The Greeke Earthquakes of February 24 and 25, 1981. A Brief Reconnaissance Report, 1981.

32. Berz and Hettler, "Earthquakes in Greece, February/March 1981"; Tifrod, "Earthquakes and Ground Rupture, Eastern Gulf of Corinth Region, Greece."

33. Berz and Hettler, "Earthquakes in Greece, February/March 1981."

34. Jirsa and Brandow, "The Greeke Earthquakes of February 24 and 25, 1981. A Brief Reconnaissance Report"; Berz and Hettler, Earthquakes in Greece, February/March 1981, 1981.

35. Ibid.

36. Ibid. 
continuity in vertical hardenings: poor quality designing and use of bad quality materials led to large-scale crumbles. ${ }^{37}$

Despite its intensity for Greek standards, the Alkyonides Island earthquake had a relatively low number of casualties. This is due to the fact that the town that suffered the higher damages is a touristic destination on the coast, which was almost uninhabited during February. ${ }^{38}$ There have been 20 casualties, but more than 100,000 people became homeless, ${ }^{39}$ and conveyed towards Athens.

Earthquake in Ano Liosia, $7^{\text {th }}$ of September 1999

At 14:56 UCT+2 of the $7^{\text {th }}$ of September of 1999 the first earth tremor happened in Ano Liosia, a suburb of north Athens. ${ }^{40}$ The earthquake measured 5.4 on the Richter scale, and 5.9 on the Moment Magnitude Scale (MMS), while the Peak Ground Acceleration (PGA) had a value between 0.05 and $0.5 \mathrm{~g}$. ${ }^{41}$ The epicentre was localised on the south-west slope of the Mount Parnitha, with a hypocenter of $8 \mathrm{~km}$ in depth, aftershocks were hundreds, and they measured between 4 and 5 on the Richter scale. ${ }^{42}$ The Ano Liosia earthquake did not cause any fractures in the Earth's crust; however, as Mount Parnitha is close to Athens (the mountain defines the north boundary of the metropolitan city of Athens), many buildings suffered from damages - they were concentrated in a $12-\mathrm{km}$ radius from the epicentre. ${ }^{43} 70,000$ buildings in Athens were surveyed for damages, divided as it follows: ${ }^{44}$

- $11 \%$ of buildings suffered severe structural damages;

- $35 \%$ of buildings suffered light structural damages;

- $54 \%$ of buildings did not suffer any structural damages.

2.500 schools were surveyed for damages, divided as it follows: ${ }^{45}$

- $2.5 \%$ of schools suffered severe structural damages;

- $9 \%$ of schools suffered light structural damages;

- $88.5 \%$ of schools did not suffer any structural damages.

Structural damages affected constructions built per the old anti-seismic policy, in which seismic values were lower than the ones envisaged in the

37. Ibid.

38. Ibid.

39. Berz and Hettler, Earthquakes in Greece, February/March 1981, 1981.

40. I. Psycharis, D. Papastamatiou, I. Taflambas and P. Carydis, Learning from Earthquakes. The Athens, Greece Earthquake of September 7, 1999 (EERI Special Earthquake Report, 1999), 1-8.

41. Ibid.

42. Ibid.

43. Ibid.

44. Ibid.

45. Ibid. 
1995 regulations. ${ }^{46}$ The most severe damages happened in Ano Liosia suburb, ${ }^{47}$ an area where unauthorised building is widespread, ${ }^{48}$ and consequently, antiseismic regulations not applied. Ano Liosia buildings collapsed because of poor quality building materials and lack of hardening systems: collapsed structures include warehouses/factories, pilotis buildings, and stone buildings of the first half of the $20^{\text {th }}$ century. ${ }^{49}$ Moreover, the earthquake provoked damages in some heritage buildings: ${ }^{50}$

- In the Temple of Olympian Zeus an old architrave crack re-opened;

- Some columns in the Erechtheion and the Parthenon experienced small rotations;

- Deep cracks in the first-floor walls appeared in the National Archaeological Museum;

- Cracks appeared in the walls of the Byzantine Museum and the Metropolitan Church.

The Ano Liosia earthquake caused 140 casualties, while circa 100.000 people became homeless. ${ }^{51}$

\section{Dome Hooping State of the Art}

The current methodology to strengthen curved masonry is to stick FRP directly on the surfaces. ${ }^{52}$ Italian guidelines CNR-DT200/2004 ${ }^{53}$ suggest the application of FRP reinforcements either at the extrados or at the intrados of masonry vaults, in order to reduce the number of plastic hinged during collapse. The FRP bands should be applied directly on the masonry surface.

Researchers Corradi et al. ${ }^{54}$ performed a lab experiment, where three fullscale masonry vaults were constructed. They aimed to test the effectiveness of FRP reinforcements, also comparing lab results to field tests in an $18^{\text {th }}$ century building in L'Aquila, Italy. This building was heavily damaged by

46. Ibid.

47. Anonymous, "Devastating Earthquakes Strike Greece and Taiwan in September," EERI Newsletter 33, no. 10 (1999): 1-3.

48. Psycharis, Papastamatiou, Taflambas and Carydis, Learning from Earthquakes. The Athens, Greece Earthquake of September 7, 1999, 1999.

49. Ibid.

50. Anonymous, "Devastating Earthquakes Strike Greece and Taiwan in September," 1999; Psycharis, Papastamatiou, Taflambas and Carydis, Learning from Earthquakes. The Athens, Greece Earthquake of September 7, 1999, 1999.

51. Ibid.

52. Laura Anania, Antonio Badalà and Giuseppe D'Agata, “The Post Strengthening of the Masonry Vaults by the $\Omega$-Wrap Technique Based on the Use of C-FRP," Construction and Building Materials 47 (2013): 1053-68.

53. CNR, CNR-DT 200/2004. Guide for the Design and Construction of Externally Bonded FRP Systems for Strengthening Concrete Structures, reported by ACI .... (CNR, 2004).

54. Marco Corradi, Antonio Borri, Giulio Castori and Kathryn Coventry, "Experimental Analysis of Dynamic Effects of FRP Reinforced Masonry Vaults," Materials 8, no. 12 (2015): 8059-71. 
the 2009 earthquake, and FRP reinforcements were applied. The authors demonstrated - through numerical data - that FRP reinforcements effectively improved the vault's behaviour. They also pointed out general benefits of using FRP strengthening systems, such as its non-invasiveness, its reversibility, and its property of non-increasing the original masses.

While Corradi et al. suggest sticking the FRP directly to the surfaces, as detachments have not been observed, Anania et al. ${ }^{55}$ propose an innovative method that includes the construction of a mortar support. This cutting-edge technique, called $\Omega$-wrap, suggests that FRP is applied around a high-resistance mortar core purpose-built, which is acting as an extra ribbon on the extrados. Around this mortar, FRP is applied, shaping a $\Omega$. This technique has been studied and developed chiefly for masonry barrel vaults, and no experiments have been performed on domed vaults yet.

At the same time, Baratta and Corbi ${ }^{56}$ are testing mathematical models to specifically identify the areas that need to be strengthened with FRP in heritage masonry vaults.

Researchers Ottoni and Blasi ${ }^{57}$ analyse the old technique of inserting tie rods to strengthen domes through a case study, the Madonna dell'Umiltà (Pistoia, Italy). They also provide some "famous" examples where encircling has been applied throughout the centuries, such as Haghia Sophia in Istanbul, Santa Maria del Fiore, San Pietro in Vaticano, and the French Pantheon - just to cite few. All these buildings have been treated with iron hooping systems. Specifically, San Pietro in Vaticano is an iconic case, as here G. Poleni had the possibility to study and develop his "orange slice" cracking approach. ${ }^{58}$ One of the few cases in history that does not need (yet) any encircling, is the Roman Pantheon. Ottoni and Blasi ${ }^{59}$ highlight that this has happened because the Pantheon dome is a perfect hemisphere and the building materials are lighter going upwards. On the other hand, Heyman ${ }^{60}$ underlines that the horizontal thrust transmitted by the dome is absorbed by the thick perimetrical walls, which are acting as a hooping. Concerning the Madonna dell'Umiltà, after dynamic testing on the existing tie-rods, Ottoni and Blasi recommend inserting a new high-resistant rid, which has actually been installed in January

55. Anania, Badalà and D’Agata, “The Post Strengthening of the Masonry Vaults by the $\Omega$-Wrap Technique Based on the Use of C-FRP," 2013.

56. Alessandro Baratta and Ottavia Corbi, "Closed-Form Solutions for FRP Strengthening of Masonry Vaults," Computers and Structures 147 (2015); Alessandro Baratta and Ottavia Corbi, "An Approach to the Positioning of FRP Provisions in Vaulted Masonry Structures," Composites Part B: Engineering 53 (2013): 334-41.

57. Federica Ottoni and Carlo Blasi, "Hooping as an Ancient Remedy for Conservation of Large Masonry Domes," International Journal of Architectural Heritage 10, no. 2-3 (2016): 164-81.

58. Jacques Heyman, "Domes," in The Stone Skeleton: Structural Engineering of Masonry Architecture (Cambridge: Cambridge University Press, 1995).

59. Ottoni and Blasi, "Hooping as an Ancient Remedy for Conservation of Large Masonry Domes," 2016.

60. Heyman, “Domes," 1995. 
$2015 .^{61}$ This new encircling has been calculated in order to be able to absorb up to the $40 \%$ of the active stress, in case one of the existing tie-rods fails.

This very brief summary foregrounds that encircling is an ancient, empirical and traditional solution that still works well. Nowadays it is widely used and presumably, it will be in the near future as well- as it can be improved and made pioneering through the use of innovative materials and techniques.

\section{Methodology}

Survey

The Dome

The dome covering Aghios Konstantinos church is not the one originally designed by Kaftantzoglou. Indeed, the current dome was built more than 20 years later than the rest of the edifice, because of funds lack. ${ }^{62}$ Kaftantzoglou planned a lighter vault, probably a double-calotte one, Byzantine-inspired. From Kaftantzoglou's drawings, it seems that the inner calotte should have been made of wood. Nevertheless, the dome that was actually built, is heavy and massive, since it is composed of calcareous stone blocks. Moreover, cupola's dimensions are much bigger than the originally planned ones, as it happens for its weight. Both the bigger dimensions and the increased weight might have had consequences on crack formation.

We surveyed the following damages (see Figure 3):

- The tambour has one deep continuous crack running over the whole perimeter;

- Vertical cracks start from the tambour base and run upwards until the windows, increasing their depth with height.

- Three-meters-high vertical cracks start from window architraves upwards.

The Arches Supporting the Dome

Dome tambour is supported by four arches. These are composed of waste bricks and blocks of calcareous stone. Thanks to the cracks, the original structure was revealed: each arch is formed by two arches. The lower one is built with bricks, and it serves as centring for the upper one.

The top arch is built with carved stone blocks. We detected the following damages (see Figure 3):

61. Ottoni and Blasi, "Hooping as an Ancient Remedy for Conservation of Large Masonry Domes," 2016.




- In the position corresponding to the hidden top arch, there is a continuous crack that follows the shape of the bottom arch. This crack is the one that confirmed our thesis that there is a hidden bottom arch.

- All arches suffer from transversal cracks, which are deeper by the keystones.

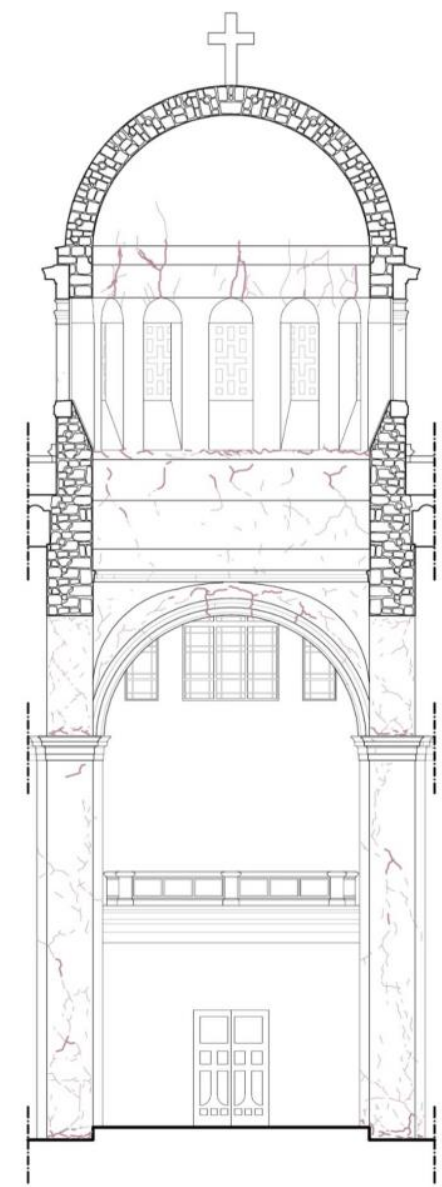

Figure 3. Cracks on the Vault

Planning Structural Consolidation

\section{Dome Hooping}

The supporting structure of the dome is composed chiefly of calcareous stones with marble stoneworks. The tambour stands on a dodecagonal structure; however, in the calculations, it has been considered as circular for simplicity. The dome has been simplified for calculations as well, since we considered it as a hemisphere. The dome is towered above by a marble cross. Instead of considering it as a punctual load, as it happens in reality, in our calculations we considered the cross as a spread load, since its contribution is negligible if compared to the vault's overall dead load. 
Through the load analysis, ${ }^{63}$ we determine $\omega$ (weight per surface, in $\left.\left[\mathrm{kN} / \mathrm{m}^{2}\right]\right)$. $\omega$ was calculated considering the dead load of each material composing the dome applied to the vault thickness. Table 1 shows the procedure above described.

Table 1. Load Analysis for the Dome

\begin{tabular}{|c|c|c|c|}
\hline \multicolumn{4}{|c|}{ DOME } \\
\hline ELEMENT & $\begin{array}{c}\text { DIMENSIONS } \\
{[\mathrm{m}]}\end{array}$ & $\begin{array}{c}\text { DEAD LOAD } \\
{\left[\mathrm{kN} / \mathrm{m}^{3}\right]}\end{array}$ & $\begin{array}{l}\text { WEIGHT } \\
{\left[\mathrm{kN} / \mathrm{m}^{2}\right]}\end{array}$ \\
\hline calcareous stone & 0.60 & 26.00 & 15.60 \\
\hline marble cross & 0.20 & 27.00 & 5.40 \\
\hline plaster & 0.60 & 30.00 & 18.00 \\
\hline copper & N/A & 0.50 & 0.50 \\
\hline TOT $\omega\left[\mathrm{kN} / \mathrm{m}^{2}\right]$ & & & 39.50 \\
\hline
\end{tabular}

As soon as we determined $\omega$, through the membrane shell theory reduction, ${ }^{64}$ we calculated the strains on the meridians on the parallels. Tension on parallels $F_{\theta}$ was calculated considering an angle of $\varphi=52^{\circ},{ }^{65}$ i.e., in correspondence of the neutral axe ${ }^{66}$ (see Figure 4). Eqs. (1), (2) and (3) show this calculation.


Figure 4. Dome Static Schematisation and Hooping Localisation

We calculated strain values on parallels as it follows:

$$
F_{\theta}=\omega \cdot a \cdot N_{\theta}
$$

63. Biagio Furiozzi, Claudio Messina and Leonardo Paolini, Prontuario per Il Calcolo Degli Elementi Strutturali (Le Monnier Scuola, 2010).

64. Carlo Gavarini, Lezioni Di Scienza Delle Costruzioni, 3rd ed. (Roma: CEA, 1996); Heyman, "Domes."

65. Heyman, "Domes," 1995.

66. Ottoni and Blasi, "Hooping as an Ancient Remedy for Conservation of Large Masonry Domes," 2016. 


$$
\begin{aligned}
& N_{\theta}=\left[\frac{1}{1+\cos \varphi}-\cos \varphi\right]_{\varphi=\frac{13}{45} \pi}^{\varphi=\frac{\pi}{2}} \\
& \rightarrow F_{\theta}=\omega \cdot a \int_{\frac{13}{45} \pi}^{\frac{\pi}{2}} N_{\theta} \cdot a \cdot d \varphi=285,68 \mathrm{kN}
\end{aligned}
$$

Where:

- $\mathrm{a}=4,91$ (radius of the neutral axe, in [m]);

- $\mathrm{F}_{\theta}=$ stress acting on parallels, in $[\mathrm{kN}]$;

- $\varphi=52$ (angle of the neutral axe, in $\left.\left[{ }^{\circ}\right]\right)$;

- $\omega=39.50$ (weight, in $\left[\mathrm{kN} / \mathrm{m}^{2}\right]$ ).

Once the active stress is determined, the hooping is dimensioned (cfr. Section "Results \& Discussion - Dome hooping").

Arches Chaining

\begin{tabular}{|c|c|c|c|c|}
\hline \multicolumn{5}{|c|}{ DOME } \\
\hline ELEMENT & $\begin{array}{c}\text { DIMENSIONS } \\
{[\mathrm{m}]}\end{array}$ & QUANTITY & $\begin{array}{c}\text { DEAD LOAD } \\
{\left[\mathrm{kN} / \mathrm{m}^{3}\right]} \\
\end{array}$ & $\begin{array}{l}\text { WEIGHT } \\
{[\mathrm{kN} / \mathrm{m}]} \\
\end{array}$ \\
\hline calcareous stones & 4.66 & 1 & 26.00 & 121.13 \\
\hline marble cross & 0.43 & 1 & 27.00 & 11.66 \\
\hline plaster & 0.23 & 1 & 30.00 & 6.89 \\
\hline copper & 0.03 & 1 & 0.50 & 0.02 \\
\hline TOT q $[\mathrm{kN} / \mathrm{m}]$ & & & & 139.70 \\
\hline \multicolumn{5}{|c|}{ TAMBOUR } \\
\hline ELEMENT & DIMENSIONS & QUANTITY & $\begin{array}{c}\text { DEAD LOAD } \\
{\left[\mathrm{kN} / \mathrm{m}^{3}\right]}\end{array}$ & $\begin{array}{l}\text { WEIGHT } \\
{[\mathrm{kN} / \mathrm{m}]} \\
\end{array}$ \\
\hline calcareous stones & 4.116 & 1 & 26.00 & 107.02 \\
\hline marble cornice & 0.863 & 1 & 27.00 & 23.31 \\
\hline marble pilasters & 0.180 & 6 & 27.00 & 29.16 \\
\hline $\begin{array}{l}\text { window marble } \\
\text { grids }\end{array}$ & 0.118 & 3 & 27.00 & 9.56 \\
\hline $\begin{array}{l}\text { concrete-framed } \\
\text { glass panels }\end{array}$ & 0.102 & 3 & 25.00 & 7.65 \\
\hline plaster & 0.329 & 1 & 30.00 & 9.87 \\
\hline TOT q $\mathrm{q}_{2}[\mathrm{kN} / \mathrm{m}]$ & & & & 186.56 \\
\hline $\begin{array}{l}\text { TOT } q=q_{1}+q_{2} \\
{[\mathrm{kN} / \mathrm{m}]}\end{array}$ & & & & 326.25 \\
\hline
\end{tabular}

Table 2. Load Analysis. Load Acting on the Arches 
Like the dome structure, the tambour as well is composed of calcareous stones with marble stoneworks (pilasters, cornices, drips), with plaster outwards and inwards. The load analysis ${ }^{67}$ has been carried out with the same simplifications adopted as for the dome calculation: the tambour is considered circular and its dead load has been split up between four supporting arches. With the considerations made above, it is possible to calculate $q$ (weight per unit meter, in $[\mathrm{kN} / \mathrm{m}])$. Table 2 below shows this calculation.

As soon as $q$ is determined, through the rotation balance shown in Eqs. (4) and (5), it is possible to calculate the pushing action $H$ (in $[\mathrm{kN}]$ ).

Figure 5 shows the parameters used to calculate $H$, and the static schematisation.

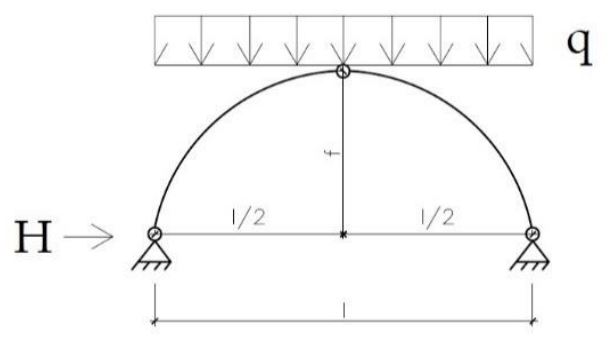

Figure 5. Arches Static Schematisation

Specifically, we considered an arch with 3 hinges, and we calculated $H$ as it follows: ${ }^{68}$

$$
\begin{aligned}
& M=\frac{q \cdot l^{2}}{8}=H \cdot f \\
& \rightarrow H=\frac{q \cdot l^{2}}{8 \cdot f}=780,91 \mathrm{kN}
\end{aligned}
$$

Where:

- $\mathrm{f}=3,72$ (sagitta, in [m]);

- $\mathrm{H}=$ pushing action, in $[\mathrm{kN} / \mathrm{m}]$;

- $1=8,44$ (length, in [m]);

- $\mathrm{q}=326,25$ (weight, in $[\mathrm{kN} / \mathrm{m}]$ );

- $\mathrm{M}=$ bending moment, in $[\mathrm{kN}]$.

67. Furiozzi, Messina, and Paolini, Prontuario per Il Calcolo Degli Elementi Strutturali, 2010.

68. Ibid. 


\section{Results \& Discussion}

\section{Dome Hooping}

Once the active stress on the dome parallels is determined, it is possible to calculate the encircling system. Fibre Reinforced Polymer (FRP) bands were chosen. This material is composed of polymers reinforced with carbon fibre and glass fibre. ${ }^{69}$ FRP bands are versatile, as they do not increase active loads $^{70}$ and they do not jeopardise nor the appearance or the geometry of the element they are applied to. Specifically, FRP's self-weight is almost negligible if compared to building materials ones. This means that - as mentioned above - FRP does not increase active loads - a property that is crucial during earthquakes. $^{71}$

For Aghios Konstantinos church we chose FRP bands also because the calculations - Eqs. (9) and (10) - show that with just one band it is possible to realise the hooping. Moreover, the application of FRP band on the Aghios Konstantinos dome can occur directly on the calcareous stones, through bonding with epoxy resin under the copper slabs. Specifically, we chose monodirectional high-resistance FRP bands with carbon fibre (OLY TEX CARBO 1200 UNI-AX HR). ${ }^{72}$ The width of the bands is $100 \mathrm{~mm}$, in order to take the arching shape into consideration.

Eqs. (6), (7), (8), (9) and (10) ${ }^{73}$ depict the encircling rod calculation.

$$
\begin{aligned}
& F_{\theta} \leq T \\
& T=A_{\text {band }} \cdot f_{t k} \\
& \rightarrow A_{\text {band }} \geq \frac{F_{\theta}}{f_{t k}}=59.05 \mathrm{~mm}^{2} \\
& A_{\text {band }}=t_{f} \cdot b_{f}=66.3 \mathrm{~mm}^{2} \\
& \rightarrow A_{\text {band }}=66,3 \mathrm{~mm}^{2}>59.05 \mathrm{~mm}^{2}
\end{aligned}
$$

Where:

- $\quad \mathrm{A}_{\text {band }}=$ FRP band area, in $\left[\mathrm{mm}^{2}\right]$;

- $\mathrm{b}_{\mathrm{f}}=100$ (FPR band width, in [mm]);

69. Olympus-FRP, OLY TEX CARBO 1200 UNI-AX HR, 2014.

70. Marco Corradi, Marco, Antonio Borri, Giulio Castori and Kathryn Coventry, "Experimental Analysis of Dynamic Effects of FRP Reinforced Masonry Vaults," Materials 8, no. 12 (2015): 8059-71.

71. Ibid.

72. Olympus-FRP, OLY TEX CARBO 1200 UNI-AX HR, 2014.

73. NTC 2008, Nuove Norme Tecniche per le Costruzioni, 2008. 
- $\mathrm{F}_{\theta}=285.68$ (active strain on parallels, in $[\mathrm{kN}]$ );

- $\mathrm{f}_{\mathrm{tk}}=4.840 \cdot 10^{3}$ (mechanical traction resistance, in $\left[\mathrm{N} / \mathrm{mm}^{2}\right]$ );

- $\mathrm{T}=$ tension that can be absorbed by FRP band, in $[\mathrm{kN}]$;

- $\mathrm{t}_{\mathrm{f}}=0.663$ (FRP band equivalent thickness, in [mm]).

Specifically, Eqs. (6) and (7) show the criteria to be followed to pre-size the FRP bands resistant area $A_{\text {band }}$. The value of $F_{\theta}$ is known from Eq. (3), as it is the active stress on the dome, and clearly it should be less than the tension $T$ that can be absorbed by the FRP bands, Eq. (7). The value of the mechanical traction resistance $f_{t k}$ has been provided by the specifications ${ }^{74}$ available on the Olympus FRP website. From Eq. (8), considering both the active strain and the resistance of FRP, it is noticeable how the resistant area $A_{\text {band }}$ needs to be major than $59.09 \mathrm{~mm}^{2}$ Choosing an FRP band width $b_{f}$ of $100 \mathrm{~mm}$, and knowing the band equivalent thickness $t_{f},{ }^{75}$ it is possible to calculate the effective resistant area $A_{\text {band }}$, as shown in Eq. (9). Finally, Eq. (10) confirms that the effective resistant area $A_{b a n d}$ is in the safe zone.

Eqs. (11), (12) and (13) perform a traction verification. It has been made according to Italian regulations CNR-DT $200 \mathrm{R} 1 / 2013$. $^{76}$

$$
\begin{aligned}
& f_{t d}=E_{f} \cdot \varepsilon_{f}=4800 \mathrm{~N} / \mathrm{mm}^{2} \\
& F_{R d}=A_{\text {band }} \cdot f_{t d}=318,24 \mathrm{kN} \\
& F_{\theta} \leq F_{R d}=285,68 \mathrm{kN}<318,24 \mathrm{kN}
\end{aligned}
$$

Where:

- $\mathrm{A}_{\text {band }}=66,3\left(\right.$ FRP band area, in $\left.\left[\mathrm{mm}^{2}\right]\right)$;

- $\mathrm{E}_{\mathrm{f}}=240$ (elasticity module, in [GPa]);

- $\varepsilon=2$ (breaking deformation, in [\%]);

- $\mathrm{F}_{\theta}=285,68$ (active stress on parallels, in $[\mathrm{kN}]$ );

- $\mathrm{F}_{\mathrm{Rd}}=$ stress resistance of FRP band, in $[\mathrm{kN}]$;

- $\mathrm{f}_{\mathrm{td}}=$ specific resistance of FRP, in $\left[\mathrm{N} / \mathrm{mm}^{2}\right]$;

Specifically, Eq. (12) calculates the stress resistance of FRP bands $F_{R d}$, as the product between the effective resistant area $A_{\text {band }}$ - previously calculated in Eq. (9) - and the specific resistance of FRP $f_{t d}$. As for above, $f_{t d}$ was calculated through the specifications ${ }^{77}$ provided by the manufacturer. Then in Eq. (13) active tension $F_{\theta}$ and FRP band resistance $F_{R d}$ are compared. As $F_{R d}$

74. Olympus-FRP, OLY TEX CARBO 1200 UNI-AX HR, 2014.

75. Ibid.

76. CNR-DT 200 R1/2013, Guide for the Design and Construction of Externally Bonded FRP Systems for Strengthening Existing Structures, 2014.

77. Olympus-FRP, OLY TEX CARBO 1200 UNI-AX HR, 2014. 
is minor than the active stress, the intervention is considered safe and verified - according to the Italian regulations above mentioned.

\section{Arches Chaining}

As soon as the push $H$ is determined, it is possible to calculate the area of the steel bars for the chaining. In this specific case, $H$ has a high value, and four bars are necessary to absorb it, as shown by Eqs. (14), (15), (16), (17) and (18).

Four 28-mm-diameter bars were selected, oversizing in favour of safety. The bars can be anchored to the arch intrados through a steel plate - not designed within this project -, which will hook the four bars at two different heights.

The chosen chaining bars are composed by austenitic-ferritic duplex AISI 2205 (22\% chromium, $5 \%$ nickel $)^{78}$ inox steel. These bars feature high resistance to corrosion, and they are supposed to be very suitable for intervention where welding operations are planned. Moreover, AISI 2205 steel is supposed to have specifications comparable to traditional inox steel, while it does not form cold crackings after welding.

The calculus below has been made according to NTC-2008. ${ }^{79}$

$$
\begin{aligned}
& H \leq T \\
& T=A_{\text {bar }} \cdot f_{y d} \\
& \rightarrow A_{\text {bar }} \geq \frac{H}{f_{y d}}=1952.27 \mathrm{~mm}^{2} \\
& \rightarrow \emptyset \geq 49.86 \mathrm{~mm} \\
& 4 \emptyset 28 \rightarrow A_{\text {bar }}=2463 \mathrm{~mm}^{2}
\end{aligned}
$$

Where:

- $\mathrm{A}_{\mathrm{bar}}=$ bar area, in $\left[\mathrm{mm}^{2}\right]$;

- $\mathrm{f}_{\mathrm{yd}}=400 * 10^{3}$ ( steel resistance, in $\left.\left[\mathrm{kN} / \mathrm{m}^{2}\right]\right)$;

- $\mathrm{H}=780,91$ (pushing action, in $[\mathrm{kN}]$ );

- $\mathrm{T}=$ tension that can be absorbed by chaining bars, in $[\mathrm{kN}]$;

- $\varnothing=$ bar diameter, in [mm].

78. http://www.outokumpu.com/sitecollectiondocuments/outokumpu-duplex-stainlesssteel-data-sheet.pdf.

79. NTC 2008, Nuove Norme Tecniche per le Costruzioni, 2008. 
Specifically, Eq. (14) shows how the tension potentially absorbable by the chaining bars $T$ needs to be lower than the active push $H$. It is possible to calculate the potentially absorbable tension $T$ as the product between the bar area $A_{b a r}$ and the characteristic steel resistance $f_{y d}$, as shown in Eq. (15). Combining Eqs. (14) and (15), it yields Eq. (16): the bar area $A_{b a r}$ needs to be major than $1952.27 \mathrm{~mm}^{2}$. Therefore, the bar diameter $\varnothing$ needs to be major than $49.86 \mathrm{~mm}$, as revealed by Eq. (17). Consequently, we can confidently say that 4 bars of $28 \mathrm{~mm}$ of diameter are sufficient to absorb the active push $H$, as demonstrated by Eq. (18).

\section{Conclusions}

This paper analyses the structural consolidation planned for the vaults in Aghios Konstantinos church, Athens. The project is part of a major one, focusing on the urban development of Athens and a whole restoration project for the church, carried out during D. Ph. Pocobelli's Master's thesis in Sapienza University of Rome.

When we surveyed the church, we noticed that a structural consolidation project was needed. Indeed, the church suffered from cracks in both the dome and its supporting arches. From archival research, we found out that possible reasons for structural damages were two big earthquakes that occurred in the nearby areas in during the last decades. Specifically, we analysed official earthquakes reports for the one in Alkyonides Islands - occurred on the 24th of February 1981 - and for the one in Ano Liosia - happened on the 7th of September 1999.

We carried out a damage survey on the dome and on the supporting arches, and we planned relative interventions. Particularly, we planned a monodyrectional high-resistance $100 \mathrm{~mm}$ FRP band with carbon fibre hooping for the dome (OLY TEX CARBO 1200 UNI-AX HR), and four 28-mm-diameter inox steel austenitic-ferritic duplex AISI 2205 (22\% chromium, 5\% nickel) bars for the arches chaining. Calculations for the dome hooping were made according to Italian regulations CNR-DT 200 R1/2013.

\section{Acknowledgements}

This work is the result of collaboration between two authors. Maria Grazia Turco wrote the paragraphs: Introduction. For a methodological preface, while Danae Phaedra Pocobelli wrote the paragraphs: Background, Methodology, Results \& Discussion, Conclusions. The paper is based on D. Ph. Pocobelli's Master thesis at the faculty of Civil and Industrial Engineering of Sapienza University of Rome, Supervisor Prof. M. G. Turco. We would like to thank Supervisors, Prof. E. Currà, Prof. D. Liberatore, Arch. A. Pouloudis, and Prof. M. Kardamitsi-Adami. We would also like to thank external advisors, Prof. D. Michalopoulos, Benaki Museum of Athens and Greek Ministry of Culture. 
Bibliography

Anania, Laura, Antonio Badalà and Giuseppe D'Agata. "The Post Strengthening of the Masonry Vaults by the $\Omega$-Wrap Technique Based on the Use of C-FRP." Construction and Building Materials 47 (2013): 1053-68. doi:10.1016/ j.conbuil dmat.2013.05.012.

Anonymous. "Devastating Earthquakes Strike Greece and Taiwan in September." EERI Newsletter 33, no. 10 (1999): 1-3.

Baratta, Alessandro and Ottavia Corbi. "An Approach to the Positioning of FRP Provisions in Vaulted Masonry Structures." Composites Part B: Engineering 53 (2013): 334-41. doi:10.1016/j.compositesb.2013.04.043.

Baratta, Alessandro and Ottavia Corbi. "Closed-Form Solutions for FRP Strengthening of Masonry Vaults." Computers and Structures 147 (2015): 244-49. doi:10.10 16/j.compstruc.2014.09.007.

Berz, G. and E. Hettler. Earthquakes in Greece, February/March 1981. Munich, 1981.

Chandra, Umesh. Conrith, Greece Earthquake of February 24, 1981. 1981

CNR. CNR-DT 200/2004. Guide for the Design and Construction of Externally Bonded FRP Systems for Strengthening Concrete Structures. Reported by ACI .... CNR, 2004. doi:10.1061/40753(171)159.

CNR-DT 200 R1/2013. Guide for the Design and Construction of Externally Bonded FRP Systems for Strengthening Existing Structures. 2014. https://www.cnr.it/ en/node/2636.

Corradi, Marco, Antonio Borri, Giulio Castori and Kathryn Coventry. "Experimental Analysis of Dynamic Effects of FRP Reinforced Masonry Vaults." Materials 8, no. 12 (2015): 8059-71. doi:10.3390/ma8125445.

D'Avino, S. "Patrimonio Edilizio: Quale Compromesso Tra Conservazione E Adeguamento Sismico?" [Built Heritage: Compromise between Conservation and Seismic Adaptation?] Il Giornale dell'Architettura. Com, no. 13 (2016).

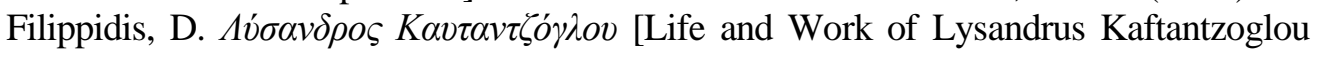
(1811-1885).] ETBA, 1995.

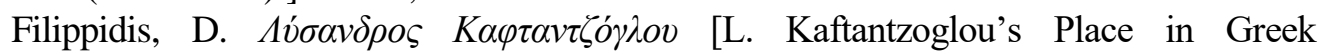
Architecture.] EIA, 1999.

Furiozzi, Biagio, Claudio Messina and Leonardo Paolini. Prontuario per Il Calcolo Degli Elementi Strutturali [Ready Reckoner for Structural Elements.] Le Monnier Scuola, 2010.

Gavarini, Carlo. Lezioni Di Scienza Delle Costruzioni [Construction Science Lessons.] 3rd Edition. Roma: CEA, 1996.

Giuffrè, A. "Sicurezza E Conservazione Dei Centri Storici. Il Caso Di Ortigia" [Hictorical Centres Security and Conservation. The Case Study of Ortigia.] In Leggendo Il Libro Delle Antiche Architetture. Aspetti Statici Del Restauro. Saggi Di A. Giuffrè 1985-1997. Edited by C. F. Carocci and C. Tocci. Rome: Laterza, 2010.

Heyman, Jacques. "Domes." In The Stone Skeleton: Structural Engineering of Masonry Architecture. Cambridge: Cambridge University Press, 1995. doi:10.1017/CBO 9781107050310.

Jirsa, James O. and Gregg E. Brandow. The Greeke Earthquakes of February 24 and 25, 1981. A Brief Reconnaissance Report. 1981.



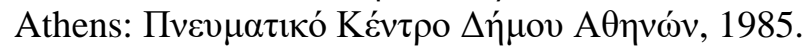


NTC 2008. Nuove Norme Tecniche per le Costruzioni [New technical regulations for constructions.] 2008. www.gazzettaufficiale.it.

Olympus-FRP. OLY TEX CARBO 1200 UNI-AX HR. 2014. https://www.olympusfrp.com/.

Ottoni, Federica and Carlo Blasi. "Hooping as an Ancient Remedy for Conservation of Large Masonry Domes." International Journal of Architectural Heritage 10, no. 2-3 (2016): 164-81. doi:10.1080/15583058.2015.1113335.

Psycharis, I., D. Papastamatiou, I. Taflambas and P. Carydis. Learning from Earthquakes. The Athens, Greece Earthquake of September 7, 1999. EERI Special Earthquake Report, 1999, 1-8.

Tifrod, Norman. Earthquakes and Ground Rupture, Eastern Gulf of Corinth Region, Greece. 1981.

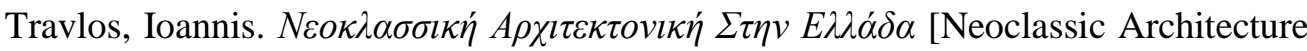

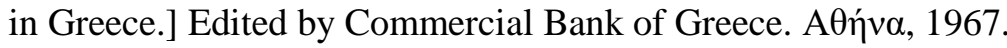

Turco, Maria Grazia and Danae Phaedra Pocobelli. "Aghios Konstantinos Church in Athens: Conservation Planning." In 3rd International Multidisciplinary Scientific Conference on Social Sciences and Arts SGEM2016, Www.sgemso cial.org, SGEM2016 Conference Proceedings. 43-50, 2016. doi:10.5593/SGEMSOCIAL 2016/HB42/S07.006.

Vivian, Frances. "Joseph Smith, Giovanni Poleni and Antonio Visentini." Italian Studies 18, no. 1 (1963): 54-66. doi:10.1179/its.1963.18.1.54. 